\title{
Understanding basaltic Plinian activity at Masaya caldera, Nicaragua
}

\author{
E. C. BAMBER ${ }^{1 *}$, F. ARZILLI ${ }^{1}$, M. POLACCI ${ }^{1}$, G. LA \\ SPinA ${ }^{1}$, M. Petrelli ${ }^{2}$, M. E. HARTLEY ${ }^{1}$, D. Di \\ GENOVA $^{3}$, J. Fellowes ${ }^{1}$, D. ChavarRía ${ }^{4}$, J. A. \\ SABAllos $^{4}$, M. DE' Michieli VitTURI ${ }^{5}$, M. R. BURTON ${ }^{1}$ \\ ${ }^{1}$ Department of Earth and Environmental Science, The \\ University of Manchester, Manchester, UK. \\ (*correspondence:emily.bamber@postgrad.manchester.ac.uk) \\ ${ }^{2}$ Department of Physics and Geology, University of Perugia, \\ Perugia, Italy \\ ${ }^{3}$ Institute of Non-Metallic Materials, Clausthal University of \\ Technology, Clausthal-Zellerfeld, Germany \\ ${ }^{4}$ INETER, Dirección General de Geofisica, Managua, \\ Nicaragua \\ ${ }^{5}$ INGV, Sezione di Pisa, Pisa, Italy
}

Plinian eruptions are the most hazardous yet enigmatic style of volcanism at basaltic systems. Masaya caldera, Nicaragua, has produced several historical Plinian eruptions, which ejected $>3 \mathrm{~km}^{3}$ of tephra over an area which now includes the capital city of Managua. However, Masaya today is characterised by degassing and low explosivity. Despite this drastic change in explosivity through time, erupted magmas show chemical homogeneity for the past 6000 years. Therefore, the cause of the explosive-effusive transition of Masaya volcano through time remains uncertain.

We present new measurements of major, trace and volatile elements from erupted products of the Fontana Lapilli (60 ka) and Masaya Triple Layer (2.1 ka) eruptions. We compare these two eruptions to understand the evolution of the Las Sierras-Masaya volcanic complex through time and if there are common conditions which favour Plinian activity. Common physico-chemical magmatic conditions that promote basaltic Plinian activity at Masaya are high microlite crystallinity up to 50 vol.\%, moderate pre-eruptive temperatures $<1100{ }^{\circ} \mathrm{C}$ and a stored $\mathrm{H}_{2} \mathrm{O}$ concentration of 2 wt.\%. We combine these petrological results with a numerical conduit model to simulate conduit processes, to understand the conditions that promote fragmentation during magma ascent. Our combined approach greatly improves our general understanding of explosive basaltic activity and provides new insight into the explosive transition of the highly hazardous Las Sierras-Masaya system. 